LA PRÁCTICA INTERNACIONAL MEXICANA 


\section{RESEÑA DE LA PRÁCTICA DEL ESTADO MEXICANO TRATADOS INTERNACIONALES CELEBRADOS POR MÉXICO (1999-2000)*}

Si hablamos de frecuencia, podemos observar que el Estado mexicano en los dos años que se reseñan tiene una proclividad por la celebración de tratados en materia de transporte aéreo, que son los acuerdos más comunes; le siguen los acuerdos en materia penal e inversiones, y después cooperación en varias áreas (científica y tecnológica, educativa, económica); en menor medida encontramos los tratados en materia de derechos humanos. Se incluyen también dos tratados de libre comercio (con Israel y con el triángulo de Estados formado por El Salvador, Guatemala y Honduras).

Sobresalen entre estos tratados por su trascendencia al Estado mexicano, un par de tratados. El primero se refiere a la frontera con los Estados Unidos: Tratado entre el Gobierno de los Estados Unidos Mexicanos y el Gobierno de los Estados Unidos de América sobre la Delimitación de la Plataforma Continental en la Región Occidental del Golfo de Más Allá de las 200 Millas Náuticas (firmado en la ciudad de Washington, D.C., el 9 de junio de 2000). Hasta la fecha (octubre de 2000) no se conocen los alcances de este tratado, que por referirse a una zona que tiene potencialmente muchas riquezas minerales, sobre todo de petróleo, y que por supuesto tocan la soberanía permanente sobre los recursos naturales, debe ser muy importante para el Estado mexicano.

El segundo tratado es el relativo al Estatuto de Roma de la Corte Penal Internacional, que por la polémica causada por una inicial reticencia de México para aceptarlo, su posterior firma, viene a ser de gran trascendencia en momentos que la jurisdicción universal, en materia de ciertos crímenes, se viene acentuando en la práctica internacional.

* Compiladores: Manuel Becerra Ramírez, Lydia S. Castillo Pérez, Georgina Flores Madrigal, Dante López Amador. 
TRATADOS BILATERALES FIRMADOS DURANTE 1999

1. Tratado entre el Gobierno de los Estados Unidos Mexicanos y el Gobierno de la República de Costa Rica sobre la Ejecución de Sentencias Penales.

Firmado en: La ciudad de San José, Costa Rica, el 15 de enero de 1999.

Publicación: 27 de mayo de 1999.

Estados parte: México y Costa Rica.

2. Acuerdo entre el Gobierno de los Estados Unidos Mexicanos y el Gobierno de los Estados Unidos de América que Enmienda el Convenio sobre Transportes Aéreos del 15 de agosto de 1960, Enmendado y Prorrogado.

Firmado en: La ciudad de Mérida, Yucatán, México, el 15 de febrero de 1999.

Publicación: 24 de agosto de 1999.

Estados parte: México y Estados Unidos.

3. Acuerdo entre el Gobierno de los Estados Unidos Mexicanos y el Gobierno de la República de Finlandia para la Promoción y Protección Recíproca de Inversiones.

Firmado en: La ciudad de México, D. F., el 22 de febrero de 1999.

publicación: 10 de julio del 2000.

Estados parte: México y Finlandia.

4. Tratado entre el Gobierno de los Estados Unidos Mexicanos y el Gobierno de Canadá Concerniente a la Prestación de Servicios por Satélite.

Firmado en: $\quad$ La ciudad de México, D. F., el 9 de abril de 1999.

Publicación: DOF, 9 de agosto del 2000.

Estados parte: México y Canadá.

5. Acuerdo por el que se modifica el Convenio sobre Transportes Aéreos entre el Gobierno de los Estados Unidos Mexicanos y el Gobierno de Canadá, del 21 de diciembre de 1961.

Celebrado por canje de notas, fechadas en la ciudad de México, D. F., el 9 de abril de 1999. 
Publicación: 9 de agosto del 2000.

Estados parte: México y Canadá.

6. Convenio Básico de Cooperación para el Desarrollo entre el Gobierno de los Estados Unidos Mexicanos y el Gobierno de la República de Cuba.

Firmado en: La ciudad de La Habana, Cuba, el 12 de abril de 1999.

Publicación: 2 de marzo del 2000.

Estados parte: México y Cuba.

7. Convenio Básico de Cooperación Científica y Técnica entre el Gobierno de los Estados Unidos Mexicanos y el Gobierno de San Kitts y Nevis.

Firmado en: La ciudad de Santo Domingo, República Dominicana, el 17 de abril de 1999.

Publicación: 2 de marzo del 2000.

Estados parte: México y San Cristóbal y Nieves.

8. Convenio entre el Gobierno de los Estados Unidos Mexicanos y el Gobierno de Rumania en materia de Cooperación para el Combate al Tráfico Ilícito de Estupefacientes y de Sustancias Psicotrópicas y Delitos Conexos.

Firmado en: La ciudad de Bucarest, Rumania, el 19 de abril de 1999.

Publicación: 11 de febrero del 2000.

Estados parte: México y Rumania.

9. Convenio sobre Transportes Aéreos entre los Estados Unidos Mexicanos y el Reino de Bélgica.

Firmado en: La ciudad de México, D. F., el 26 de abril de 1999.

Publicación: 2 de marzo del 2000.

Estados parte: México y Bélgica.

10. Convenio sobre Transporte Aéreo entre el Gobierno de los Estados Unidos Mexicanos y el Gobierno de Nueva Zelanda.

Firmado en: La ciudad de México, D. F., el 14 de mayo de 1999.

Publicación: 1 de marzo del 2000.

Estados parte: México y Nueva Zelanda. 
11. Acuerdo de Cooperación Mutua entre los Estados Unidos Mexicanos y el Reino de España para el Intercambio de Información respecto de Operaciones Financieras realizadas a través de Instituciones Financieras para Prevenir y Combatir Operaciones de Procedencia Ilícita o de Lavado de Dinero.

Firmado en: La ciudad de Madrid, España, el 24 de mayo de 1999.

Publicación: 11 de febrero del 2000.

Estados parte: México y España.

12. Convenio Básico de Cooperación Científica y Tecnológica entre el Gobierno de los Estados Unidos Mexicanos y el Gobierno de la República Helénica.

Firmado en: La ciudad de Atenas, Grecia, el 14 de junio de 1999.

Publicación: 25 de agosto del 2000.

Estados parte: México y República Helénica.

13. Tratado de Cooperación entre el Gobierno de los Estados Unidos Mexicanos y el Gobierno de la República Oriental del Uruguay sobre Asistencia Jurídica Mutua en materia Penal.

Firmado en: La ciudad de Montevideo, Uruguay, el 30 de junio de 1999.

Publicación: 1 de marzo del 2000.

Estados parte: México y Uruguay.

14. Acuerdo entre los Estados Unidos Mexicanos y la República Oriental del Uruguay para la Promoción y la Protección Recíprocas de las Inversiones.

Firmado en: La ciudad de Montevideo, Uruguay, el 30 de junio de 1999.

Publicación: 1 de marzo del 2000.

Estados parte: México y Uruguay.

15. Convenio entre los Estados Unidos Mexicanos y el Estado de Israel para Evitar la Doble Imposición e Impedir la Evasión Fiscal en materia de Impuestos sobre la Renta y sobre el Patrimonio.

Firmado en: La ciudad de México, D. F., el 20 de julio de 1999.

Publicación: 11 de agosto del 2000.

Estados parte: México e Israel. 
16. Acuerdo por el que se Modifica el Convenio sobre Transporte Aéreo entre el Gobierno de los Estados Unidos Mexicanos y el Gobierno de la República de Cuba, firmado el 9 de agosto de 1991.

Celebrado por canje de Notas, fechadas en la ciudad de La Habana, Cuba, el 19 de mayo y 20 de agosto de 1999.

Publicación: 7 de agosto del 2000.

Estados parte: México y Cuba.

17. Convenio de Cooperación Educativa y Cultural entre el Gobierno de los Estados Unidos Mexicanos y el Gobierno de Côte d'Ivoire.

Firmado en: La ciudad de México, D. F., el 5 de octubre de 1999.

Publicación: 1 de marzo del 2000.

Estados parte: México y Costa de Marfil.

18. Acuerdo entre los Estados Unidos Mexicanos y la República Portuguesa sobre la Promoción y Protección Recíproca de las Inversiones.

Firmado en: La ciudad de México, D. F., el 11 de noviembre de 1999.

Publicación: 12 de julio del 2000.

Estados parte: México y Portugal.

19. Convenio entre los Estados Unidos Mexicanos y la República Portuguesa para Evitar la Doble Imposición e Impedir la Evasión Fiscal en materia de Impuestos sobre la Renta.

Firmado en: La ciudad de México, D. F., el 11 de noviembre de 1999.

20. Acuerdo entre el Gobierno de los Estados Unidos Mexicanos y el Gobierno de la República Italiana para la Promoción y Protección Recíproca de las Inversiones.

Firmado en: La ciudad de Roma, Italia, el 24 de noviembre de 1999. Publicación: 10 de julio del 2000.

Estados parte: México e Italia.

21. Acuerdo de Comercio y Cooperación Económica entre el Gobierno de los Estados Unidos Mexicanos y el Gobierno de la República Checa.

Firmado en: La ciudad de México, D. F., el 26 de noviembre de 1999. 
Publicación: 7 de agosto del 2000.

Estados parte: México y República Checa.

22. Convenio de Cooperación Educativa y Cultural entre el Gobierno de los Estados Unidos Mexicanos y el Gobierno de la República Federal de Nigeria.

Firmado en: La ciudad de México, el 8 de diciembre de 1999.

Publicación: 12 de julio del 2000.

Estados parte: México y Nigeria.

TRATADOS MULTILATERALES FIRMADOS DURANTE 1999

1. Memorándum de Entendimiento en materia de Cooperación para la Atención de Víctimas de Minas Terrestres en Países de Centroamérica entre los Estados Unidos Mexicanos, Canadá y la Organización Panamericana de la Salud.

Firmado en: La ciudad de México, D. F., el 11 de enero de 1999.

2. Memorándum de Entendimiento sobre Cooperación Trilateral México-Finlandia-Guatemala.

Firmado en: La ciudad de México, D. F., el 22 de febrero de 1999.

Publicación: 1 de marzo del 2000.

Estados parte: México, Finlandia y Guatemala.

3. Acuerdo entre los Estados Miembros y Miembros Asociados de la Asociación de Estado del Caribe para la Cooperación Regional en materia de Desastres Naturales.

Firmado en: La ciudad de Santo Domingo, República Dominicana, el 17 de abril de 1999.

Firmada por México, el 17 de abril de 1999.

Publicación: 10 de julio del 2000.

4. Convención Interamericana sobre Transparencia en la Adquisición de Armas Convencionales.

Firmada en la ciudad de Guatemala, Guatemala, el 7 de junio de 1999.

Firmada por México, el 7 de junio de 1999. 
5. Convención Interamericana para la Eliminación de Todas las Formas de Discriminación contra Personas con Discapacidad.

Firmada en la ciudad de Guatemala, Guatemala, el 7 de junio de 1999. Firmada por México, el 8 de junio de 1999.

Publicación: 9 de agosto del 2000.

6. Protocolo relativo a las Inmunidades del Banco de Liquidaciones Internacionales

Adoptado en la ciudad de Bruselas, Bélgica, el 30 de julio de 1936.

Firmado por México el 24 de junio de 1999.

Publicación: 11 de febrero del 2000.

7. Acta Constitutiva de la Asociación de Estados Iberoamericanos para el Desarrollo de las Bibliotecas Nacionales de los Países de Iberoamérica - ABINIA.

Firmada en la ciudad de Lima, Perú, el 12 de octubre de 1999.

Firmada por México el 12 de octubre de 1999.

Publicación: 10 de julio del 2000.

8. Protocolo al Convenio para la Cooperación en el marco de la Conferencia Iberoamericana para la Constitución de la Secretaría de Cooperación Iberoamericana (SECIB) y Estatutos de la Secretaría de Cooperación Iberoamericana.

Firmado en la ciudad de La Habana, Cuba, el 15 de noviembre de 1999.

Firmado por México el 15 de noviembre de 1999.

9. Protocolo Facultativo de la Convención sobre la Eliminación de Todas las Formas de Discriminación contra la Mujer.

Adoptado por la Asamblea General de las Naciones Unidas, el 6 de octubre de 1999.

Firmado por México el 10 de diciembre de 1999.

Publicación de la aprobación del retiro de la declaración interpretativa que el gobierno de los Estados Unidos formuló al aprobar dicha convención: 1 de marzo del 2000.

10. Protocolo sobre Privilegios e Inmunidades de la Asociación de Estados del Caribe.

Firmado en la ciudad de Panamá, República de Panamá, el 13 de diciembre de 1999. 
TRATADOS BILATERALES FIRMADOS DURANTE 2000

1. Tratado para la Recuperación y Devolución de Vehículos y Aeronaves Robados o materia de Disposición Ilícita entre el Gobierno de los Estados Unidos Mexicanos y el Gobierno de la República de Costa Rica.

Firmado en: La ciudad de México, el 11 de enero de 2000.

Publicación: 21 de julio del 2000.

Estados parte: México y Costa Rica.

2. Tratado entre el Gobierno de los Estados Unidos Mexicanos y el Gobierno de Nicaragua sobre la Ejecución de Sentencias Penales.

Firmado en la ciudad de México, el 14 de febrero de 2000.

3. Tratado de Libre Comercio entre los Estados Unidos Mexicanos y el Estado de Israel.

Firmado en: La ciudad de México, el 10 de abril de 2000.

Publicación: 19 de julio del 2000.

Estados parte: México e Israel.

4. Acuerdo entre el Gobierno de los Estados Unidos Mexicanos y el Gobierno del Reino de Dinamarca para la Promoción y Protección Recíproca de las Inversiones.

Firmado en: La ciudad de México, el 13 de abril de 2000.

Publicación: 12 de julio del 2000.

Estados parte: México y Dinamarca.

5. Convenio entre los Estados Unidos Mexicanos y la República del Perú sobre Asistencia Jurídica en materia Penal.

Firmado en la ciudad de México, el 2 de mayo de 2000.

6. Tratado de Extradición entre los Estados Unidos Mexicanos y la República del Perú.

Firmado en la ciudad de México, el 2 de mayo de 2000.

7. Convenio de Cooperación en materia de Turismo entre el Gobierno de los Estados Unidos Mexicanos y el Gobierno de la República de Panamá.

Firmado en la ciudad de México, el 22 de mayo de 2000. 
8. Acuerdo entre el Gobierno de los Estados Unidos Mexicanos y el Gobierno de los Estados Unidos de América por el que se modifica y prorroga el Convenio para el Establecimiento de la Comisión México-Estados Unidos para el Intercambio Educativo y Cultural suscrito en Monterrey el 27 de noviembre de 1990.

Celebrado por canje de Notas, fechadas en la ciudad de Washington, D.C., E.U.A., el 18 de mayo de 2000.

9. Tratado entre el Gobierno de los Estados Unidos Mexicanos y el Gobierno de los Estados Unidos de América sobre la Delimitación de la Plataforma Continental en la Región Occidental del Golfo de Más Allá de las 200 Millas Náuticas.

Firmado en la ciudad de Washington, D. C., el 9 de junio de 2000.

10. Convenio de Cooperación Educativa y Cultural entre el Gobierno de los Estados Unidos Mexicanos y el Gobierno de la República Libanesa.

Firmado en la ciudad de Beirut, el 21 de junio de 2000.

11. Convenio de Cooperación Científica y Técnica entre el Gobierno de los Estados Unidos Mexicanos y el Gobierno de la República Libanesa.

Firmado en la ciudad de Beirut, el 21 de junio de 2000.

12. Tratado de Libre Comercio entre los Estados Unidos Mexicanos y las Repúblicas de El salvador, Guatemala y Honduras.

Firmado en la ciudad de México, el 29 de junio de 2000.

13. Acuerdo entre los Estados Unidos Mexicanos y Rumania para Evitar la Doble Imposición e Impedir la Evasión Fiscal en materia de Impuestos sobre la Renta.

Firmado en la ciudad de México, el 20 de julio de 2000.

14. Acuerdo entre el Gobierno de los Estados Unidos Mexicanos y el Gobierno de los Estados Unidos de América en relación al Uso de la Banda de 2310-2360 MHz.

Firmado en la ciudad de México, el 24 de julio de 2000. 
15. Acuerdo entre el Gobierno de los Estados Unidos Mexicanos y el Gobierno de los Estados Unidos de América para Establecer una Comisión de Salud Fronteriza México-Estados Unidos.

Firmado en la ciudad de Washington, D. C., el 14 de julio de 2000 y en la ciudad de México, el 24 de julio de 2000.

\section{TRATADOS MULTILATERALES FIRMADOS DURANTE 2000}

1 Protocolo de Cartagena sobre Seguridad de la Biotecnología del Convenio sobre la Diversidad Biológica.

Adoptado en Montreal, el 29 de enero de 2000.

Firma de México el 24 de mayo de 2000.

2. Actas Finales de la Conferencia Mundial de Radiocomunicaciones (CMR-2000) de la Unión Internacional de Telecomunicaciones (UIT). Adoptadas en la ciudad de Estambul, Turquía, el 2 de junio de 2000.

Firmadas por México el 2 de junio de 2000.

3. Protocolo para Enmendar la Convención de 1949 para el Establecimiento de una Comisión Interamericana del Atún Tropical.

Firmado en la ciudad de Guayaquil, Ecuador, el 11 de junio de 1999.

Firmado por México el 22 de agosto de 2000.

4. Protocolo sobre Privilegios e Inmunidades de la Asociación de Estados del Caribe.

Firmado en la ciudad de

Firmado por México el 30 de agosto de 2000.

5. Protocolo Facultativo de la Convención sobre los Derechos del Niño relativo a la Venta de Niños, la Prostitución Infantil y la Utilización de Niños en la Pornografía.

Adoptado por la Asamblea General de las Naciones Unidas el 25 de mayo de 2000.

Firmado por México el 7 de septiembre de 2000. 
6. Protocolo Facultativo de la Convención sobre los Derechos del Niño relativo a la Participación de Niños en los Conflictos Armados.

Adoptado por la Asamblea General de las Naciones Unidas el 25 de mayo de 2000.

Firmado por México el 7 de septiembre de 2000.

7. Convenio Internacional para la Represión de la Financiación del Terrorismo.

Adoptado por la Asamblea General de las Naciones Unidas el 9 de diciembre de 1999.

Firmado por México el 7 de septiembre de 2000.

8. Estatuto de Roma de la Corte Penal Internacional.

Adoptado en Roma, el 17 de julio de 1998.

Firmado por México el 7 de septiembre de 2000.

\section{OTROS TRATADOS INTERNACIONALES PUBLICADOS \\ EN EL DOF DURANTE 1999-2000}

1. Decreto por el que se aprueba el Acuerdo General de Cooperación entre el Gobierno de los Estados Unidos Mexicanos y el Gobierno de la República de Sudáfrica.

Lugar de firma: La ciudad de Nueva York.

Fecha de firma: 23 de septiembre de 1998.

Publicación: 18 de enero de 1999.

Estados parte: México y Sudáfrica.

Categoría: Bilateral.

2. Decreto promulgatorio de la Convención Interamericana para Prevenir, Sancionar y Erradicar la Violencia contra la Mujer, Convención de Belem do Pará.

Lugar de firma: La ciudad de Belem do Pará, Brasil.

Fecha de firma: 9 de junio de 1994.

Publicación: 19 de enero de 1999.

Categoría: multilateral.

3. Decreto por el que se aprueba la Convención Internacional sobre la Protección de los Derechos de todos los Trabajadores Migratorios y 
de sus Familiares, adoptada por la Asamblea General de las Naciones Unidas.

Lugar de firma: Nueva York.

Fecha de firma: 18 de diciembre de 1990.

Publicación: 10 de febrero de 1999.

Categoría: multilateral.

4. Decreto promulgatorio del Convenio de Cooperación Técnica entre el Gobierno de los Estados Unidos Mexicanos y el Gobierno de la República Federal de Alemania.

Lugar de firma: ciudad de Bonn.

Fecha de firma: 8 de octubre de 1997.

Publicación: 15 de febrero de 1999.

Estados parte: México y Alemania

Categoría: bilateral.

5. Decreto promulgatorio del Convenio entre el Gobierno de los Estados Unidos Mexicanos y el Gobierno de la República de Indonesia sobre cooperación Técnica y Científica.

Lugar de firma: Jakarta, Indonesia.

Fecha de firma: 2 de julio de 1997.

Publicación: 15 de febrero de 1999.

Estados parte: México e Indonesia.

Categoría: bilateral.

6. Decreto por el que se aprueba el Acuerdo entre los Estados Unidos Mexicanos y la Unión Económica Belgo-Luxemburguesa sobre la Promoción y Protección Recíproca de Inversiones.

Lugar de firma: ciudad de México.

Fecha de firma: 27 de agosto de 1998.

Publicación: 16 de febrero de 1999.

Categoría: multilateral.

7. Decreto por el que se aprueba el Acuerdo entre los Estados Unidos Mexicanos el Gobierno de la República Federal de Alemania sobre la Promoción y Protección Recíproca de las Inversiones.

Lugar de firma: ciudad de México.

Fecha de firma: 25 de agosto de 1998.

Publicación: 16 de febrero de 1999. 
Estados parte: México y Alemania.

Categoría: bilateral.

8. Decreto por el que se aprueba el Acuerdo entre el Gobierno de los Estados Unidos Mexicanos y el gobierno de la República de Austria sobre la Promoción y Protección de las Inversiones.

Lugar de firma: ciudad de Viena.

Fecha de firma: 29 de junio de 1998.

Publicación: 16 de febrero de 1999.

Estados parte: México y Austria.

Categoría: bilateral.

9. Decreto por el que se aprueba el Acuerdo de Comercio entre el Gobierno de los Estados Unidos Mexicanos y el Gobierno de Rumania.

Lugar de firma: ciudad de México.

Fecha de firma: 3 de septiembre de 1998.

Publicación: 16 de febrero de 1999.

Estados parte: México y Rumania.

Categoría: bilateral.

10. Decreto por el que se aprueba el Acuerdo de Cooperación Técnica en materia de Seguridad Pública entre el Gobierno de los Estados Unidos Mexicanos y el Gobierno de la República Francesa.

Lugar de firma: ciudad de México.

Fecha de firma: 12 de noviembre de 1998.

Publicación: 16 de febrero de 1999.

Estados parte: México y Francia.

Categoría: bilateral.

11. Decreto por el que se aprueba el Tratado de Asistencia Jurídica Mutua en Materia Penal entre los Estados Unidos Mexicanos y la República Portuguesa.

Lugar de firma: ciudad de Lisboa.

Fecha de firma: 20 de octubre de 1998.

Publicación: 16 de febrero de 1999.

Estados parte: México y Portugal.

Categoría: bilateral. 
12. Decreto por el que se aprueba el Tratado de Extradición entre los Estados Unidos Mexicanos y la República Portuguesa.

Lugar de firma: ciudad de Lisboa.

Fecha de firma: 20 de octubre de 1998.

Publicación: 16 de febrero de 1999.

Estados parte: México y Portugal.

Categoría: bilateral.

13. Decreto por el que se aprueba la resolución a13-1 ampliación del área geográfica de la CLAC para la incorporación de otros Estados de América, adoptada durante la XIII Asamblea de la Comisión Latinoamericana de Aviación Civil.

Lugar de firma: ciudad de Santiago, Chile.

Fecha de firma: 21 de julio de 1998.

Publicación: 16 de febrero de 1999.

Categoría: multilateral.

14. Decreto por el que se aprueban las modificaciones a los estatutos del grupo de países latinoamericanos y del Caribe exportadores de azúcar (GEPLACEA), aprobadas por la XXXIII asamblea plenaria del grupo.

Lugar de firma: Boca del Río, Veracruz, México.

Fecha de firma: 24 de octubre de 1997.

Publicación: 16 de febrero de 1999.

Categoría: multilateral.

15. Decreto promulgatorio de la Convención Americana sobre Derechos Humanos "Pacto de San José de Costa Rica".

Lugar de firma: San José, Costa Rica.

Fecha de firma: 22 de noviembre de 1969.

Publicación: 24 de febrero de 1999.

Categoría: multilateral.

16. Aclaración al decreto promulgatorio de la Declaración para el Reconocimiento de la Competencia Contenciosa de la Corte Internacional de Derechos Humanos, publicado el 24 de febrero de 1999.

Publicación: 25 de febrero de 1999.

Categoría: multilateral. 
17. Decreto por el que se aprueba la Convención para Combatir el Cohecho de Servidores Públicos Extranjeros en Transacciones Comerciales Internacionales.

Lugar de firma: ciudad de París.

Fecha de firma: 17 de diciembre de 1997.

Publicación: 12 de mayo de 1999.

Categoría: multilateral.

18. Decreto promulgatorio del Acuerdo de Sede entre el Gobierno de los Estados Unidos Mexicanos y la Comisión México-Estados Unidos para el Intercambio Educativo y Cultural.

Lugar de firma: ciudad de México.

Fecha de firma: 25 de mayo de 1998.

Publicación: 17 de mayo de 1999.

Estados parte: México y Estados Unidos.

Categoría: bilateral.

19. Decreto promulgatorio del Acuerdo sobre el Programa Internacional para la Conservación de los Delfines.

Lugar de firma: Washington, D.C., E.U.

Fecha de firma: 21 de mayo de 1998.

Publicación: 17 de mayo de 1999.

Categoría: multilateral.

20. Decreto por el que se aprueba el Acuerdo entre el Gobierno de los Estados Unidos Mexicanos y el Gobierno de la República Argentina Concerniente a la Reciprocidad en el uso de Satélites y la Transmisión y Recepción de Señales desde Satélites para la Prestación de Servicios por Satélite a Usuarios en los Estados Unidos Mexicanos y la República Argentina.

Lugar de firma: ciudad de México.

Fecha de firma: 26 de noviembre de 1997.

Publicación: 24 de mayo de 1999.

Estados parte: México y Argentina.

Categoría: bilateral. 
21. Decreto por el que se aprueba el Acuerdo de Cooperación Económica y Financiera entre los Estados Unidos Mexicanos y el Reino de España.

Lugar de firma: ciudad de México.

Fecha de firma: 3 de diciembre de 1998.

Publicación: 26 de mayo de 1999.

Estados parte: México y España.

Categoría: bilateral.

22. Decreto por el que se aprueba el Acuerdo de Cooperación Turística entre el Gobierno de los Estados Unidos Mexicanos y el Gobierno de la República de Colombia.

Lugar de firma: ciudad de México.

Fecha de firma: 7 de diciembre de 1998.

Publicación: 26 de mayo de 1999.

Estados parte: México y Colombia.

Categoría: bilateral.

23. Decreto por el que se aprueba la Convención entre los Estados Unidos de América y la República de Costa Rica para el Establecimiento de una Comisión Internacional de Atún Tropical.

Lugar de firma: Washington, D. C.

Fecha de firma: 31 de mayo de 1949.

Publicación: 3 de junio de 1999.

Categoría: multilateral.

24. Decreto promulgatorio de la Convención entre los Estados Unidos de América y la República de Costa Rica para el Establecimiento de una Comisión Interamericana de Atún Tropical.

Lugar de firma: Washington, D. C.

Fecha de firma: 31 de mayo de 1949.

Publicación: 19 de julio de 1999.

Categoría: multilateral.

25. Decreto promulgatorio del Convenio Básico de Cooperación Técnica y Científica entre el Gobierno de los Estados Unidos Mexicanos y el Gobierno de la República de Filipinas.

Lugar de firma: ciudad de México.

Fecha de firma: 12 de mayo de 1997. 
Publicación: 19 de julio de 1999.

Estados parte: México y Filipinas.

Categoría: bilateral.

26. Decreto promulgatorio del Convenio de Cooperación Educativa y Cultural entre el Gobierno de los Estados Unidos Mexicanos y el Gobierno de la República Tunecina.

Lugar de firma: ciudad de México.

Fecha de firma: 26 de octubre de 1998.

Publicación: 19 de julio de 1999.

Estados parte: México y Túnez.

Categoría: bilateral.

27. Decreto promulgatorio del Tratado de Libre Comercio entre la República de Chile y los Estados Unidos Mexicanos.

Lugar de firma: ciudad de Santiago de Chile.

Fecha de firma: 17 de abril de 1998.

Publicación: 28 de julio de 1999.

Estados parte: México y Chile.

Categoría: bilateral.

28. Decreto por el que se aprueba el Protocolo Relativo al Texto Auténtico en seis idiomas del Convenio sobre Aviación Civil (Chicago, 1944) y del Protocolo relativo a una enmienda al citado Convenio adoptados en la Conferencia Internacional sobre el Texto Chino Auténtico del Convenio sobre Aviación Civil Internacional (Chicago, 1944).

Lugar de firma: Montreal, Canadá.

Fecha de firma: 1 de octubre de 1998.

Publicación: 24 de agosto de 1999.

Categoría: multilateral.

29. Decreto por el que se aprueba el Tratado de la OMPI sobre Interpretación o ejecución de fonogramas, adoptado en el marco de la Conferencia Diplomática sobre ciertas Cuestiones de Derecho de Autor y Derechos Conexos de la Organización Mundial de la Propiedad Intelectual.

Lugar de firma: Ginebra, Suiza.

Fecha de firma: 20 de diciembre de 1996. 
Publicación: 24 de agosto de 1999.

Categoría: multilateral.

30. Decreto promulgatorio del Convenio sobre Transporte Aéreo entre el Gobierno de los Estados Unidos Mexicanos y el Gobierno de la República de Chile.

Lugar de firma: ciudad de México.

Fecha de firma: 14 de enero de 1997.

Publicación: 13 de septiembre de 1999.

Estados parte: México y Chile.

Categoría: bilateral.

31. Decreto promulgatorio de las actas finales de la Conferencia Mundial en Radiocomunicaciones (CMR-95), adoptadas en el marco de la Unión Internacional de Telecomunicaciones (UIT).

Lugar de firma: ciudad de Ginebra, Suiza.

Fecha de firma: 17 de noviembre de 1995.

Publicación: 27 de septiembre de 1999.

Categoría: multilateral.

32. Decreto promulgatorio del Convenio de Reconocimiento de Certificados de Estudios de Nivel Primario y Medio no Técnico o sus Denominaciones equivalentes entre los Estados Unidos Mexicanos y la República Argentina.

Lugar de firma: ciudad de México.

Fecha de firma: 26 de noviembre de 1997.

Publicación: 27 de septiembre de 1999.

Estados parte: México y Argentina.

Categoría: bilateral.

33. Decreto por el que se aprueba el Tratado de Prohibición Completa de los Ensayos Nucleares, adoptado por la Asamblea General de las Naciones Unidas.

Lugar de firma: Nueva York.

Fecha de firma: 10 de septiembre de 1996.

Publicación: 1 de octubre de 1999.

Categoría: multilateral. 
34. Decreto promulgatorio del Acuerdo por el que se modifica el Convenio sobre Transporte Aéreo entre el Gobierno de los Estados Unidos Mexicanos y el Gobierno de la República de Cuba, formalizado mediante canje de notas.

Lugar de firma: La Habana, Cuba.

Fecha de firma: 24 de junio de 1998.

Publicación: 11 de septiembre de 1999.

Estados parte: México y Cuba.

Categoría: bilateral.

35. Aclaración del decreto de promulgación del Acuerdo entre los Estados Unidos Mexicanos y la Comunidad Europea para la Cooperación en Materia de Control de los Precursores y Sustancias Químicas Utilizados con Frecuencia en la Fabricación Ilícita de Estupefacientes o Sustancias Psicotrópicas, publicado el 7 de enero de 1998.

Publicación: 23 de diciembre de 1999.

Categoría: multilateral.

36. Decreto promulgatorio del Tratado de Prohibición Completa de los Ensayos Nucleares, adoptado por la Asamblea General de las Naciones Unidas.

Lugar de firma: Nueva York.

Fecha de firma: 10 de septiembre de 1996.

Publicación: $\quad 27$ de diciembre de 1999.

Categoría: multilateral.

37. Decreto por el que se aprueba el nuevo texto revisado de la Convención Internacional de Protección Fitosanitaria, aprobado mediante la resolución 12/97 del 29o. periodo de sesiones de la Conferencia de la Organización de las Naciones Unidas para la Agricultura y la Alimentación (FAO).

Lugar de firma: Roma, Italia.

Fecha de firma: 17 de noviembre de 1997.

Publicación: 29 de diciembre de 1999.

Categoría: multilateral.

38. Decreto por el que se aprueba el Protocolo de Kyoto de la Convención Marco de las Naciones Unidas sobre Cambio Climático.

Lugar de firma: ciudad de Kyoto. 
Fecha de firma: 11 de diciembre de 1997.

Publicación: 1 de septiembre del 2000.

Categoría: multilateral.

39. Decreto promulgatorio de la Convención sobre el Estatuto de los Apátridas.

Lugar de firma: Nueva York.

Fecha de firma: 28 de septiembre de 1954.

Publicación: 25 de agosto del 2000.

Categoría: multilateral.

40. Decreto promulgatorio de la Convención sobre el Estatuto de los Refugiados.

Lugar de firma: Ginebra.

Fecha de firma: 28 de julio de 1951.

Publicación: 25 de agosto del 2000.

Categoría: multilateral.

41. Decreto promulgatorio del Protocolo sobre el Estatuto de los Refugiados.

Lugar de firma: Nueva York.

Fecha de firma: 31 de enero de 1967.

Publicación: 25 de agosto del 2000.

Categoría: multilateral.

42. Decreto por el que se aprueban las actas finales de la Conferencia Mundial de Radiocomunicaciones (CMR-97), adoptadas en el marco de la Unión Internacional de Telecomunicaciones (UIT).

Lugar de firma: Ginebra, Suiza.

Fecha de firma: 21 de noviembre de 1997.

Publicación: 32 de agosto del 2000.

Categoría: multilateral.

43. Decreto promulgatorio del Convenio entre los Estados Unidos Mexicanos e Irlanda para evitar la doble imposición e impedir la evasión fiscal en materia de impuestos sobre la renta y sobre las ganancias de capital.

Lugar de firma: ciudad de dublín.

Fecha de firma: 22 de octubre de 1998. 
Publicación: 9 de agosto del 2000.

Estados parte: México e Irlanda.

Categoría: bilateral.

44. Decreto por el que se aprueba el Acuerdo por el que se modifica el Acuerdo entre el Gobierno de los Estados Unidos Mexicanos y el Gobierno de los Estados Unidos de América concerniente a la asignación de frecuencias y uso de la banda 2500 a $2686 \mathrm{mhz}$ a lo largo de la frontera México-Estados Unidos.

Lugar de firma: Washington, D. C.

Fecha de firma: 11 de agosto de 1992.

Publicación: 9 de agosto del 2000.

Estados parte: México y Estados Unidos.

Categoría: bilateral.

45. Decreto por el que se aprueba el Convenio para la Unificación de ciertas Reglas para el Transporte Aéreo Internacional.

Lugar de firma: Montreal, Canadá.

Fecha de firma: 28 de mayo de 1999.

Publicación: 9 de agosto del 2000.

Estados parte: México y Canadá.

Categoría: bilateral.

46. Decreto por el que se aprueba el Arreglo de Estrasburgo relativo a la Clasificación Internacional de Patentes del 24 de marzo de 1971 y enmendado el 28 de septiembre de 1979.

Fecha de firma: 24 de marzo de 1971

Publicación: 7 de agosto del 2000.

Categoría: multilateral.

47. Decreto por el que se aprueba el Arreglo de Lisboa relativo a la Protección de las Denominaciones de Origen y su Registro Internacional del 31 de octubre de 1958, revisado en Estocolmo el 14 de julio de 1967 y modificado el 28 de septiembre de 1979 y su reglamento adoptado el 5 de octubre de 1976.

Fecha de firma: 31 de octubre de 1958.

Publicación: 7 de agosto del 2000.

Categoría: multilateral. 
48. Decreto por el que se aprueba el Arreglo de Locarno que establece una clasificación internacional para los dibujos y modelos industriales, firmado en Locarno el 8 de octubre de 1968 y enmendado el 28 de septiembre de 1979.

Lugar de firma: Locarno.

Fecha de firma: 8 de octubre de 1968.

Publicación: 7 de agosto del 2000.

Categoría: multilateral.

49. Decreto por el que se aprueba el Acuerdo de Viena por el que se establece una clasificación internacional de los elementos figurativos de las marcas, establecido en Viena el 12 de junio de 1973 y enmendado el 1 de octubre de 1985.

Lugar de firma: ciudad de Viena.

Fecha de firma: 12 de junio de 1973.

Publicación: 7 de agosto del 2000.

Categoría: multilateral.

50. Decreto por el que se aprueba el Acuerdo por el que se modifica el Convenio sobre Transporte Aéreo entre los Estados Unidos Mexicanos y la República de Cuba, Firmado en la ciudad de México, el nueve de agosto de mil novecientos noventa y uno, formalizado mediante canje de notas, fechadas en la ciudad de La Habana, Cuba, el diecinueve de mayo y veinte de agosto de mil novecientos noventa y nueve.

Lugar de firma: ciudad de México.

Fecha de firma: 9 de agosto de 1991.

Publicación: 7 de agosto del 2000.

Estados parte: México y Cuba.

Categoría: bilateral.

51. Decreto promulgatorio de la resolución a12-5 enmiendas al Estatuto de la CLAC, adoptada durante la XII Asamblea de la Comisión Latinoamericana de Aviación Civil, celebrada en la ciudad de Panamá, del cinco al ocho de noviembre de mil novecientos noventa y seis.

Lugar de firma: ciudad de Panamá.

Fecha de firma: 5 de noviembre de 1996. 
Publicación: $\quad 4$ de agosto del 2000.

Categoría: multilateral.

52. Decreto promulgatorio del Acuerdo para promover el cumplimiento de las medidas internacionales de conservación y ordenación por los buques pesqueros que pescan en alta mar, adoptado durante la 27a. Conferencia General de la Organización de las Naciones Unidas para la Agricultura y Alimentación (FAO).

Lugar de firma: ciudad de Roma, Italia.

Fecha de firma: 24 de noviembre de 1993.

Publicación: 4 de agosto del 2000.

Categoría: multilateral.

53. Decreto promulgatorio del protocolo entre el Gobierno de los Estados Unidos Mexicanos y el Gobierno de los Estados Unidos de América por el que se modifica la Convención para la Protección de las Aves Migratorias y Mamíferos Cinegéticos.

Publicación: 21 de julio del 2000.

Estados parte: México y Estados Unidos.

Categoría: bilateral.

54. Decreto por el que se aprueba el Acuerdo entre el Gobierno de los Estados Unidos Mexicanos y el Gobierno de la República Helénica sobre Asistencia Jurídica Mutua en Materia Penal.

Lugar de firma: ciudad de Atenas.

Fecha de firma: 25 de octubre de 1999.

Publicación: 21 de julio del 2000.

Estados parte: México y República Helénica.

Categoría: bilateral.

55. Decreto promulgatorio del Convenio entre el Gobierno de los Estados Unidos Mexicanos y el Gobierno de la República Dominicana sobre Cooperación en Materia de Combate al Tráfico Ilícito, Abuso de Estupefacientes y Sustancias Psicotrópicos y Delitos Conexos.

Lugar de firma: ciudad de México.

Fecha de firma: 18 de agosto de 1997.

Publicación: 14 de julio del 2000.

Estados parte: México y República Dominicana.

Categoría: bilateral. 
56. Decreto promulgatorio del Convenio Básico de Cooperación Técnica y Científica entre el Gobierno de los Estados Unidos Mexicanos y el Gobierno de la República de Nicaragua.

Lugar de firma: ciudad de México.

Fecha de firma: 31 de octubre de 1995.

Publicación: 14 de julio del 2000.

Estados parte: México y Nicaragua

Categoría: bilateral.

57. Decreto promulgatorio del Convenio de Cooperación Educativa y Cultural entre el Gobierno de los Estados Unidos Mexicanos y el Gobierno de la República de Eslovenia.

Lugar de firma: Nueva York.

Fecha de firma: 23 de septiembre de 1996.

Publicación: 12 de julio del 2000.

Estados parte: México y Eslovenia.

58. Decreto promulgatorio del Convenio sobre Cooperación Científica y Tecnológica entre el Gobierno de los Estados Unidos Mexicanos y el Gobierno de la República de Polonia.

Lugar de firma: ciudad de México.

Fecha de firma: 30 de noviembre de 1998.

Publicación: 12 de julio del 2000.

Estados parte: México y Polonia.

Categoría: bilateral.

59. Decreto promulgatorio del Convenio de Cooperación en las Áreas de la Educación, la Cultura y el Deporte entre el Gobierno de los Estados Unidos Mexicanos y el Gobierno de la República de Bolivia.

Lugar de firma: ciudad de México.

Fecha de firma: 11 de diciembre de 1998.

Publicación: 10 de julio del 2000.

Estados parte: México y Bolivia.

Categoría: bilateral.

60. Decreto promulgatorio del Acuerdo para la Promoción y Protección Recíproca de las Inversiones entre los Estados Unidos Mexicanos y el Reino de los Países Bajos.

Lugar de firma: ciudad de México. 
Fecha de firma: 13 de mayo de 1998.

Publicación: 10 de julio del 2000.

Estados parte: México y Países Bajos.

Categoría: bilateral.

61. Decreto por el que se aprueba el Tratado de Extradición entre el Gobierno de los Estados Unidos Mexicanos y el Gobierno de la República Helénica.

Lugar de firma: ciudad de Atenas.

Fecha de firma: 25 de octubre de 1999.

Publicación: 10 de julio del 2000.

Estados parte: México y República Helénica.

Categoría: bilateral.

62. Decreto por el que se aprueba la Convención Interamericana para la Protección y Conservación de las Tortugas Marinas.

Lugar de firma: Caracas.

Fecha de firma: 1 de diciembre de 1996.

Publicación: 10 de julio del 2000.

Categoría: multilateral.

63. Resolución por la que se modifican las bases de coordinación para regular la navegación en las zonas marinas mexicanas y autorizar los arribos y estancias a puertos mexicanos de buques de Estados destinados a fines no comerciales y de guerra extranjeros o con esa función.

Publicación: 7 de julio del 2000.

Categoría: multilateral.

64. Decreto promulgatorio del Acuerdo de Asociación Económica, Concertación Política y Cooperación entre los Estados Unidos Mexicanos y la Comunidad Europea y sus Estados Miembros.

Publicación: 26 de junio del 2000.

Categoría: multilateral.

65. Decreto promulgatorio del Convenio entre el Gobierno de los Estados Unidos Mexicanos y el Gobierno de Gran Ducado de Luxemburgo sobre Transporte Aéreo.

Lugar de firma: ciudad de México. 
Fecha de firma: 19 de marzo de 1996.

Publicación: 14 de junio del 2000.

Estados parte: México y Luxemburgo.

Categoría: bilateral.

66. Decreto promulgatorio del Convenio Básico de Cooperación Científica, Técnica y Tecnológica entre el Gobierno de los Estados Unidos Mexicanos y el Gobierno de Ucrania.

Lugar de firma: ciudad de México.

Fecha de firma: 25 de septiembre de 1997.

Publicación: 13 de junio del 2000.

Estados parte: México y Ucrania.

Categoría: bilateral.

67. Decreto por el que se aprueba el Convenio sobre la prohibición de las peores formas de trabajo infantil y la acción inmediata para su eliminación, adoptado en la Conferencia General de la OIT durante su 87 reunión.

Lugar de firma: Ginebra, Suiza

Fecha de firma: 7 de junio de 1959.

Publicación: 1 de junio del 2000.

Categoría: multilateral.

68. Decreto promulgatorio del Convenio de Cooperación y Coproducción Cinematográfica entre el Gobierno de los Estados Unidos Mexicanos y el Gobierno de la República Argentina.

Lugar de firma: Buenos Aires.

Fecha de firma: 13 de noviembre de 1996.

Publicación: 16 de mayo del 2000.

Estados parte: México y Argentina.

Categoría: bilateral.

69. Decreto promulgatorio del Convenio entre los Estados Unidos Mexicanos y la República de Chile, para evitar la doble imposición e impedir la evasión fiscal en materia de impuestos sobre la renta y el patrimonio.

Lugar de firma: Santiago de Chile.

Fecha de firma: 17 de abril de 1998.

Publicación: 12 de mayo de 2000. 
Estados parte: México y Chile.

Categoría: bilateral.

70. Decreto promulgatorio del Tratado de Extradición entre los Estados Unidos Mexicanos y la República Portuguesa.

Lugar de firma: Lisboa.

Fecha de firma: 20 de octubre de 1998.

Publicación: 9 de mayo de 2000.

Estados parte: México y Portugal.

Categoría: bilateral.

71. Decreto promulgatorio del Acuerdo General de Cooperación entre los Estados Unidos Mexicanos y el Reino de Marruecos.

Lugar de firma: ciudad de México.

Fecha de firma: 9 de octubre de 1991.

Publicación: 3 de mayo del 2000.

Estados parte: México y Marruecos.

Categoría: bilateral.

72. Decreto promulgatorio del Convenio de Cooperación Cultural y Educativa entre los Estados Unidos Mexicanos y la República Argentina.

Lugar de firma: ciudad de México.

Fecha de firma: 26 de noviembre de 1997.

Publicación: 2 de mayo del 2000.

Estados parte: México y Argentina.

Categoría: bilateral.

73. Decreto promulgatorio del Convenio de Cooperación Regional para la Creación y Funcionamiento del Centro de Cooperación Regional para la Educación de los Adultos en América Latina y el Caribe.

Lugar de firma: ciudad de México.

Fecha de firma: 19 de octubre de 1990.

Publicación: $\quad 8$ de mayo del 2000.

Categoría: multilateral.

74. Decreto por el que se aprueba el Acuerdo de Cooperación para la Promoción de la Ciencia y la Tecnología Nucleares en América Latina y el Caribe.

Lugar de firma: Viena. 
Fecha de firma: 24 de septiembre de 1998.

Publicación: 2 de marzo del 2000.

Categoría: multilateral.

75. Decreto por el que se aprueba el Convenio sobre Cooperación Científica y Tecnológica entre el Gobierno de los Estados Unidos Mexicanos y el Gobierno de la República de Polonia.

Lugar de firma: ciudad de México.

Fecha de firma: 30 de noviembre de 1998.

Publicación: 2 de marzo del 2000.

Estados parte: México y Polonia.

Categoría: bilateral.

76. Decreto por el que se aprueba el Convenio de Cooperación en las Áreas de Educación, Cultura y Deporte entre el Gobierno de los Estados Unidos Mexicanos y el Gobierno de la República de Bolivia.

Lugar de firma: ciudad de México.

Fecha de firma: 11 de diciembre de 1998.

Publicación: 2 de marzo del 2000.

Estados parte: México y Bolivia.

Categoría: bilateral.

77. Decreto por el que se aprueba el Convenio relativo a la Organización Hidrográfica Internacional.

Lugar de firma: Mónaco.

Fecha de firma: 3 de mayo de 1967.

Publicación: 2 de marzo del 2000.

Categoría: multilateral.

78. Decreto por el que se aprueba el Tratado de la OMPI sobre Derechos de Autor, adoptado en el marco de la Conferencia Diplomática sobre Ciertas Cuestiones de Derecho de Autor y Derechos Conexos de la Organización Mundial de la Propiedad Intelectual.

Lugar de firma: ciudad de Ginebra, Suiza.

Fecha de firma: 20 de diciembre de 1996.

Publicación: 1 de marzo del 2000. 
79. Decreto por el que se aprueba el Protocolo relativo a las Inmunidades del Banco de Pagos Internacionales.

Lugar de firma: Bruselas.

Fecha de firma: 30 de julio de 1936.

Publicación: 11 de febrero del 2000.

Categoría: multilateral. 